\title{
AGENCY AND UBUNTU: EXPLORING THE POSSIBILITY OF COMPLEMENTARITY IN POSTGRADUATE STUDY
}

\section{Langutani M. Masehela}

\section{INTRODUCTION}

Doing research for the purpose of postgraduate study is a challenge in developing countries, in this case, with specific reference to South Africa. Mutula (2009) shares the challenges of doing postgraduate studies in Africa, while Magano (2011) reports on the experiences of female postgraduate students in South Africa. These researchers confirm the existence of challenges encountered by students when studying towards a postgraduate degree in the African context. I share some of the sentiments in this chapter. Such challenges may be intensified when Africanised socio-cultural approaches that emphasise the collective (for example, the notion of Ubuntu) and westernised academic demands that elevate the notion of student agency clash. Thus postgraduate students in Africa often find themselves operating in a multiplicity of systems which tend to obscure the development of true student agency due to the dominance of westernised discourses. As such, the social exigencies of cultural or family demands are often not compatible with the postgraduate project that is shaped by western ideologies, values and norms ${ }^{1}$.

This chapter is mainly motivated by my experiences as an academic, wife, mother, and extended family and community member. Though I understand the idiosyncratic nature of each postgraduate student's experience, I believe my experiences might find relevance to that of a wider range of African postgraduate students. In this chapter, I highlight hindrances that make it difficult for me, during my postgraduate studies, to exercise agency due to clashes in the multiple systems that I operated in as a human

1 Also see the second chapter by Zondi Mkhabela and Liezel Frick that speaks to this notion of knowledge construction. 
being ${ }^{2}$. Furthermore, my intention is to make a contribution towards strengthening relationships between supervisors and students. Experiences that I share may assist African and non-African supervisors to understand their students and appreciate them as social beings ${ }^{3}$. Students may also benefit from alternative ways of dealing with challenges that might delay the completion of their studies.

In this chapter, I focus on how postgraduate demands and African practices of Ubuntu in a South African context may clash. The chapter first elaborates on the notion of agency as explicated by Margaret Archer's (Archer 1995, 1996 and 2000) theory of social realism, which is rooted in Roy Bhaskar's (1979) philosophy of science known as critical realism. This background is followed by a description of the meaning of postgraduate study as it is embedded in the westernised, individualised notion of agency. The chapter then continues to explore the notion of Ubuntu in the African context, which imbibes the idea of collectivity as opposed to the individualistic westernised notion of agency. But instead of juxtaposing these notions, I argue that the two concepts can be complementary if supervisors and students can draw on the strengths of both agency and Ubuntu in an African context.

\section{AGENCY AS A DRIVER OF THE POSTGRADUATE PROJECT}

The notion of agency necessitates the existence of agents, in this case, postgraduate students and their supervisors. For Archer (2007), agents are social beings born with a sense of self who occupy social roles over time. She argues that this sense of self is not socially constructed because it comes into existence prior to our socialisation. Although the development of the sense of self takes place in the individual, this does not mean that structure (for example policies, social systems, organisations or institutions) and culture (norms, values, ideologies or beliefs) are not acknowledged, but only that sociality or the society is not key to this process. This implies that the sense of self is superior to that of the social. It is interesting to note that although Archer emphasises the primacy of this sense of self, she also provides an account of agency in socio-cultural contexts (Archer 1996).

Archer (1996) identifies three layers of agency: the person, the agent and the actor. The person relates to the sense of self with which we are born. The agent and the actor then emerge as a result of interaction with social contexts. Within an African

2 Being caught between conflicting systems is also addressed by Andre van der Bijl (Chapter 7) in relation to work and study, Soraya Abdulatief (Chapter 6) with regards to being a firstgeneration student, and Guin Lourens (Chapter 9) on being a studying working mother.

3 In this regard, also see the chapter by Bella Vilakazi (Chapter 5) that addresses studentsupervisor relationships. 
social milieu, it appears that the latter two layers of agency (the agent and the actor) may obscure the person (sense of self) to an extent of losing it due to the dominant (western) discourses that emerge in a postgraduate student's study context. I realised during my studies that I was losing my "personhood" in one way or the other to the actor in an African social context, for example a neighbour, mother and aunt. Many a time I have to put others first and my needs and concerns last. Archer (1996) furthermore distinguishes between two types of agents: primary and corporate agents. According to Archer (2000:263), primary agents are "collectivities sharing the same life chances". A group of black working-class students from rural backgrounds enrolled at an institution could thus be considered primary agents. Primary agents can transform themselves into corporate agents in pursuit of change. They would do this by exercising the personal emergent powers and properties accorded to them in interaction with the cultural and structural emergent powers and properties they encounter. Archer (1995:258) defines corporate agents as groups "who are aware of what they want, can articulate it to themselves and others, and have organised in order to get it, can engage in concerted action to re-shape or retain the structural or cultural feature in question." Later in the chapter, I illustrate how I evolved from being a primary agent in my context and became a corporate agent by partnering with other individuals in order to practice the African collective practices in the solitary westernised academic exercise of studying towards a postgraduate degree. This I did through joining a study group that aims to catapult progress of its members' studies despite our clashing ideologies and systems ${ }^{4}$.

The final concept used by Archer (1996) in her account of agency is that of the social actor. Social actors are individuals who occupy roles which themselves have powers and properties that cannot be reduced to those of the person who occupies them. In an academic context, the supervisor, head of department or dean would all be examples of such roles. Although the roles have powers and properties, social actors exercise their incumbency of roles in different ways, depending on their own powers and properties. In the case of postgraduate supervision, supervisors have roles that are coupled with powers and properties that influence their supervision style and choices. Therefore, while supervisors acknowledge their powers and properties they can also exercise their agency, the sense of self. Supervisors could, for instance, establish a mutual relationship between themselves and their students in such a way that there is flexibility that enable students to meet both study and family demands.

4 Also see Part 5 of this book that highlights the value of such social practices during postgraduate study. 


\section{POSTGRADUATE STUDY IN SOUTH AFRICA}

Given this background on the notion of agency, the link between the westernised culture of studying for yourself and Archer's notion of agency as the sense of self is noticeable. Postgraduate study, which is rooted in the western education system, is founded upon dominant discourses that may influence the relationship between supervisor and student. The issue of student agency becomes critical in that the student has to contribute in setting up terms and conditions of the student-supervisor relationship and take ownership of the research project. A prospective student might exercise agency by finding out how many successful Master's or doctoral students were supervised by the potential supervisor. How long did these students take to complete their studies? What are the potential supervisor's research interests, and how does this match the prospective student's research interests?

However, agency not only lies with the student - both universities and supervisors also have agency within the postgraduate system. Universities use postgraduate programmes to develop research capacity and generate the high-end skills required for a functional economy and to address complex issues (Mutula 2009). However, both students and supervisors may encounter challenges that prevent them from achieving this end when societal and academic demands clash. I therefore argue that student agency in postgraduate studies is not an option but a condition with which every student needs to engage.

Agency within the student-supervisor relationship plays a critical role in completing a study successfully. The way in which postgraduate programmes are structured in the South African context encourages students to work in silos as the apprenticeship model is still the dominant form (ASSAf 2010:64). As a result, students may have limited chances of interacting with their peers, especially in non-laboratory fields of study. Therefore, the experience of doing postgraduate studies can be intimidating to the student who is being inducted into a culture of studying independently without the involvement of family and peers following a similar study programme. Westernised systems of knowledge production furthermore promote and encourage student agency, which are often in conflict with traditional African ways of being. As a result, postgraduate studies in the African context may present challenging experiences to the student. The notion of Ubuntu, which promotes the idea of doing things collectively or operating as a collective, provides some insights into how to understand this alternative way of being.

\section{THE NOTION OF UBUNTU}

Le Grange (2012:331) describes Ubuntu as a concept that is derived from proverbial expressions (aphorisms) found in several languages in Africa south of the 
Sahara. Ubuntu is not only a linguistic concept, but it has a normative connotation embodying how we ought to relate to each other and our moral obligations towards each other. Du Toit (2011:253) views the concept of Ubuntu as a humanist African philosophy indispensable to African socio-ethical reflection. As such, Ubuntu elucidates the joint rootedness and interdependence of persons, which is often not well pronounced in western traditions of knowledge production. In this section, I share possible circumstances that I personally encountered during my postgraduate studies rooted in the Ubuntu tradition that might be in conflict with such westernised forms of education, particularly as it relates to the notion of agency.

Postgraduate study is constituted by the western epistemological idea of "educationfor-me" which is in conflict with "education for us" (Du Toit 2011 :253). Postgraduate supervisors therefore need to have an understanding of their students' heritage and belief systems if they want to help these students develop their agency. I found my supervisor acquainted with such because of the noticeable flexibility I observed during our interaction. African postgraduate students, especially those that live in rural communities such as myself, belong to communities that continue to strongly uphold the idea of sharing, which could be sharing of pain, pleasure, food, chores or any other activities. This is evident in the way people greet - not only inquiring about your well-being but also about the well-being of the rest of the family. For instance, in my tribe we say, "minihani" (the literal translation of "how are you" in Xitsonga). The "mi" in "minihani" is the plural of "you" and also signifies respect. One is always attached to other members of the family (who may not necessarily be your husband, children, siblings or parents). Cousins, for instance, first or second, are equally close to one and deserve one's attention as much as any other close family member. This form of connectedness might impact directly or indirectly on postgraduate study progress because students are often expected to compromise their time and space due to the setup in a family environment. For example, it is customary to be fully involved in funeral and wedding preparations of not only your closest family members, but also that of your neighbour, second cousin, or friend. Ubuntu can become a "spider web" relationship when the student finds it impossible to escape the circumstances. A typical spider web makes it very difficult for you to escape because of the nature of its form and its ability to trap you when you want to rescue yourself from it. I realised that, as an actor or agent in my community, I ran the risk of losing my sense of self as described by Archer (2000). In the next section, I share how I found the middle ground between agency and Ubuntu to save myself from losing myself in either my studies or community life. 


\section{FINDING THE MIDDLE GROUND: AGENCY AND UBUNTU AS COMPLEMENTARY PERSPECTIVES IN POSTGRADUATE SUPERVISION}

My experience of doctoral studies has brought about a strong-willed resolve to deal with circumstances where my studies and family responsibilities have competed for my attention. I would suggest three key ideas that I adopted in my journey to complement Ubuntu with agency.

Firstly, I joined a study group. Study groups connect colleagues with similar interests to form a special interest group where they agree to share research-related challenges among themselves. If there is one in your circle, consider joining it. If there is none, become the pioneer of such a group. Do not think about the financial implications for such a group - you will only be required to agree on the frequency of your meetings and the venue could be in someone's home on a rotational basis. More often than not I would find myself unable to attend these meetings because of the physical distance between my home and my group members. I then resorted to joining them through social networks. Social networks can be very useful for this purpose. Recognise that knowledge transfer is key in your journey towards completing your study as it helps you to understand what you are learning even better. Share the study material that you might come across no matter how short an article may be or how big a book might be. As you share and discuss study materials with your study group, you will notice that it also detangles some of those threshold concepts that you have been grappling with in your own research. At the institution where I completed my doctoral study, there were structured "doctoral weeks" that I found beneficial. These doctoral weeks were coupled with an active online learning site where the coordinator of the doctoral programme regularly engaged with everyone by providing relevant sources, sparking debates about a common topic of interest, and keeping candidates in the loop around issues related to higher education at national and international levels. I found this approach to be a powerful tool to eliminate loneliness during my postgraduate journey. Not only did they provide me with the opportunity to develop my own agency in the postgraduate environment, the interaction with other postgraduate students and scholars built a sense of Ubuntu within the study group itself. Study groups may therefore help students and supervisors to find the middle ground between the notions of agency and Ubuntu.

Secondly, I had to vehemently develop basic research skills, such as proposal-writing workshops where topics such as crafting research questions and identifying a research problem are discussed. This is especially important if you are not working in an academic environment. If the department where you are enrolled does not offer such skills development workshops, ask your supervisor to suggest such opportunities. 
Developing your research skills will help you become more eloquent in your field of study, and improve your agency when you need to consult with your supervisor or other experts. Well-developed research skills gained at the onset of your study will save you much time in the long term, which may, in turn, enable you to engage with your family and community when the need arises.

Thirdly, I developed a planned study schedule. I would decide how long the next study session should take and what I would be reading or writing about. In case I wanted to start a new chapter, I tried to sketch a rough outline of that chapter and then decide which subsection I would work on next. This made my study sessions much more productive. Part-time students are pressurised to juggle work, family, societal and postgraduate responsibilities. I had to use my annual leave days to get uninterrupted study time. Supervisors also need to provide space within supervisory relationships and study schedules to accommodate unforeseen circumstances students might face during the course of their studies. Involvement in such activities remains an act of Ubuntu for the student, but it is important to decide how involved you should be considering your study obligations. You will have to prepare family members and neighbours that you will be less visible at such occasions for the duration of your studies. Also communicate openly and regularly with your supervisor so that they may have a greater understanding for your circumstances (which might be different to theirs). Such communication is a form of agency, while at the same time recognising the need for Ubuntu in the South African context.

\section{CONCLUSION}

In this chapter I explored the possibility of complementing two contrasting notions, that of Ubuntu and the notion of student agency during a postgraduate journey of African students. Finding the middle ground between the two notions has potential to levelling the ground between supervisor and student challenges. It is possible for such students to meet social demands and responsibilities with a stronger sense of agency, while supervisors could benefit from having a better understanding of their students and accordingly devise more effective supervisory strategies.

\section{REFERENCES}

Academy of Science of South Africa. (2010). The PhD study: Consensus Report. Pretoria, South Africa: ASSAf.

Archer, M. S. (1995). Social realist theory: The morphogenetic approach. Cambridge, UK: Cambridge University Press. http://dx.doi.org/10.1017/CBO9780511557675

Archer, M. S. (1996). Culture and agency: The place of culture in social theory. Cambridge, UK: Cambridge University Press. http://dx.doi.org/10.1017/CBO978051 1557668 


\section{POSTGRADUATE STUDY IN SOUTH AFRICA}

Archer, M. S. (2000). Being Human. Cambridge, UK: Cambridge University Press. http://dx.doi.org/10.1017/CBO9780511488733

Archer, M. S. (2007). Making our way through the world. Cambridge, UK: Cambridge University Press. http://dx.doi.org/10.1017/CBO9780511618932

Bhaskar, R. (1979). The possibility of naturalism. A philosophical critique of the contemporary human sciences. Brighton, UK: Harvester.

Du Toit, C. (201 1). Off-campus education as a "we-ness": A Case for Ubuntu as a Theoretical Framework. HURIA Journal of The Open University of Tanzania Volume, 13 August, 2012 ISSN 08566739. Special Issue: Edited Proceedings of the Third ACDE (African Council for Distance Education) Conference Held in Dar es Salaam, Tanzania on 12-15 July, 2011.

Le Grange, L. (2012). Ubuntu, ukama, environment and moral education. Journal of Moral Education, 3(41):329-340. http://dx.doi.org/10.1080/03057240.2012.691631

Magano, M.D. (201 1). The Social and Emotional Challenges of Female Postgraduate Students in South Africa. Journal of Social Sciences, 29(3):205-212.

Mutula, S. M. (2009). Challenges of postgraduate research: global context, African perspectives. Keynote address delivered at the University of Zululand, 10th DLIS Annual Conference, from 9-10 September 2009. 